\title{
2-Acryloyl-4,5-methylenedioxyphenol: A Small Molecule Endowed with Antidermatophytic Activity
}

\author{
Marco Zuccolo ${ }^{\mathrm{a}}$, Sabrina Dallavalle ${ }^{\mathrm{a},{ }^{*}}$, Raffaella Cincinelli ${ }^{\mathrm{a}}$, Luce Mattio ${ }^{\mathrm{a}}$, Stefania Mazzini ${ }^{\mathrm{a}}$ \\ Michelandrea De Cesare $^{b}$ and Loana Musso ${ }^{a}$
}

\author{
${ }^{a}$ Department of Food, Environmental and Nutritional Sciences, Division of Chemistry and Molecular Biology, \\ Università degli Studi di Milano, via Celoria 2, 20133 Milano, Italy; ${ }^{b}$ Department of Experimental Oncology and \\ Molecular Medicine Fondazione IRCCS - Istituto Nazionale dei Tumori, Via Amadeo 42, 20133 Milano, Italy
}

\begin{abstract}
Background: Superficial fungal infections are the most common fungal diseases in humans, affecting more than $25 \%$ of the population worldwide.Methods: In the present study, we have investigated the activity of kakuol, a natural compound isolated from the rhizomes of Asarum sieboldii, and some analogues, against various dermatophytes and pharmacologically relevant yeasts.

Results: One of the tested compounds, 2-acryloyl-4,5-methylenedioxyphenol, showed a broadspectrum activity against most of the fungal species assayed, resulting particularly effective against dermatophyte strains (MIC values in the range of $0.25-0.5 \mu \mathrm{g} / \mathrm{mL}$, two/four-fold lower than the positive control miconazole).
\end{abstract}

A R T I C L E H I S T O R Y
Received: November 08, 2017
Revised: July 10, 2018
Accepted: July 19, 2018
DOI:
I0.2174/1570180815666180803115347

. Conclusion: The ressils sugst

Conclusion: The results suggest that this molecule can be considered a promising starting point for the development of new antifungal compounds.

Keywords: Kakuol, Asarum sieboldii, antifungal agents, Candida albicans, dermatophytes, 3,4-methylenedioxyphenol.

\section{INTRODUCTION}

Superficial fungal infections involving skin, nails and mucosal surfaces, are the most common fungal diseases in humans, affecting more than $25 \%$ of the general population worldwide. Such infections are often recalcitrant to therapy and reduce the quality of life of infected individuals [1,2]. Cutaneous and subcutaneous mycoses are caused by dematophytes like Epidermophyton, Microsporum, and Trichophyton, while mucosal infections are mainly caused by opportunistic yeasts belonging to the Candida genus [3].

Moreover, fungal species belonging to genera Candida, Aspergillus, Cryptococcus, Mucor, Pneumocystis produce invasive fungal infections associated with unacceptably high mortality rates. Such infections are very common in immunosuppressed individuals as a result of aggressive therapies (e.g. anticancer chemotherapy, long-term corticosteroids treatment, or organ transplant) or immunosuppressive infections such as HIV/AIDS [1, 2].

Although many antifungal compounds have been developed during the last twenty years, they are confined to

*Address correspondence to this author at the Department of Food, Environmental and Nutritional Sciences, Division of Chemistry and Molecular Biology, Università degli Studi di Milano, via Celoria 2, 20133 Milano, Italy; Tel: +39 2 50316818; Fax: +39 2 50316801;

E-mail: sabrina.dallavalle@unimi.it relatively few chemical classes. In addition, the emergence of fungal strains resistant to the current drugs on the market has reduced the effectiveness of the treatments [4-6]. Thus, the identification of novel scaffolds endowed with antifungal activity is becoming extremely urgent.

Naturally occurring substances from fungi, bacteria and higher plants are important sources of molecules with antifungal properties [7]. As a part of a research program aimed at developing new antifungal agents, we focused our attention on kakuol (compound 1) (Fig. 1), a secondary metabolite isolated from the rhizomes of Asarum sieboldii [8]. In a previous paper, we reported the activity of kakuol and a series of analogues against several plant pathogens [9]. The most promising derivative was 2-acryloyl-4,5methylenedioxyphenol (compund 2) (Fig. 1), which showed a remarkable in vitro antifungal activity.

In the present study, we have extended our investigation to test the efficacy of kakuol and analogues numbered as compounds 2-4 in Fig. 1 against various pharmacologically relevant dermatophytes and yeasts.

\section{MATERIALS AND METHODS}

\subsection{Chemistry}

All reagents and solvents were reagent-grade or were purified by standard methods before use. Solvents were 
<smiles>CCC(=O)c1cc2c(cc1O)OCO2</smiles><smiles>C=CC(=O)c1cc2c(cc1O)OCO2</smiles>

kakuol (1)<smiles>C=CCCC(=O)c1cc2c(cc1O)OCO2</smiles>

3<smiles>C=CC(=O)c1cc2c(cc1OC)OCO2</smiles>

4
Fig. (1). Structure of the natural compound kakuol (1) and analogues 2-4.

routinely distilled prior to use. Reactions requiring anhydrous conditions were performed under a positive nitrogen flow, and glassware was oven-dried. Anal. TLC: Fluka TLC plates (silica gel $60 \mathrm{~F} 254$, aluminium foil). Spectra: in $\mathrm{CDCl}_{3}$ at r.t. on a Bruker AMX-300 spectrometer operating at $300 \mathrm{MHz}$; chemical shifts $(\delta)$ and coupling constants $(J)$ are reported in ppm and in $\mathrm{Hz}$, respectively. Kakuol and compounds $\mathbf{2}$ and $\mathbf{3}$ were prepared as previously reported [9].

\section{1-(6-Methoxybenzo[1,3]dioxol-5-yl)propenone (Compound 4)}

To a solution of compound $2(50.0 \mathrm{mg}, 0.26 \mathrm{mmol})$ in acetone $(2 \mathrm{~mL}), \mathrm{K}_{2} \mathrm{CO}_{3}(36.0 \mathrm{mg}, 0.26 \mathrm{mmol})$ and $\mathrm{CH}_{3} \mathrm{I}$ $(88.0 \mathrm{mg}, 0.62 \mathrm{mmol})$ were added and the resulting mixture was heated at reflux for $10 \mathrm{~h}$. The solvent was evaporated, then EtOAc $(5 \mathrm{~mL})$ and water $(5 \mathrm{~mL})$ were added. The organic phase was separated and dried with $\mathrm{Na}_{2} \mathrm{SO}_{4}$. Filtration and evaporation of the solvent under reduced pressure gave $59 \mathrm{mg}(100 \%)$ of the title compound as a white sticky solid. ${ }^{1} \mathrm{H}$ NMR $\left(300 \mathrm{MHz}, \mathrm{CDCl}_{3}\right) \delta: 7.30(1 \mathrm{H}$, s); $7.14(1 \mathrm{H}, \mathrm{dd}, J=16.6,10.4 \mathrm{~Hz}) ; 6.58(1 \mathrm{H}, \mathrm{s}) ; 6.32(1 \mathrm{H}$, $\mathrm{dd}, J=16.6,1.5 \mathrm{~Hz}) ; 6.02(2 \mathrm{H}, \mathrm{s}) ; 5.20(1 \mathrm{H}, \mathrm{dd}, J=10.4$, $1.5 \mathrm{~Hz}) ; 3.82(3 \mathrm{H}, \mathrm{s})$. Anal. Calcd. for $\mathrm{C}_{11} \mathrm{H}_{10} \mathrm{O}_{4}$ : C. 64.07; H. 4.89. Found: 64.31 ; H. 4.87.

\subsection{Biological Studies}

\subsubsection{Fungal Strains}

Stocks of tested strains belonging to yeast (14 strains), filamentous (8 strains) and dermatophyte (14 strains) fungi, were either obtained from international institutes typified collections (American Type Culture Collection ATCC, National Collection of Pathogenic Fungi member of UKNCC, Istituto Superiore di Sanità, Rome), or were isolated in the hospital Istituto Dermopatico dell'Immacolata, Rome.

\subsubsection{Antifungal Susceptibility Testing}

Standard antifungal susceptibility testing was performed in accord with the Clinical and Laboratory Standards Institute's and European Committee on Antimicrobial Susceptibility Testing rules [10, 11] using RPMI 1640 medium (Glucose 2\%) with L-glutamine, without sodium bicarbonate as sensitivity test medium, and Sabouraud broth as a growth medium to prepare the inocula.

\subsubsection{Preparation of Inocula}

Yeasts. An overnight culture of the fungi in Sabouraud broth was diluted 1:10 in the same sterile medium. The obtained fungal suspensions were adjusted with the use of $0.5 \mathrm{McF}$ arland turbidity standard at $1 \times 10^{5}$ cells $/ \mathrm{mL}$ using the test medium (RPMI 1640).

\subsubsection{Filamentous Fungi and Dermatophytes}

Three-seven days old cultures in Sabouraud agar were harvested with a scraping device using Sabouraud broth supplemented with Tween $80(0.5 \%)$. The obtained suspension of the conidia was counted at a Bürker camera and then standardized in the test medium (RPMI 1640) to $1 \times 10^{5}$ cell $/ \mathrm{mL}$.

\subsubsection{Preparation of Formulates}

Test items $(10 \mathrm{mg})$ were dissolved in DMSO $(10 \mathrm{~mL})$ and then diluted in the test medium (RPMI 1640) to reach the final value of $256 \mu \mathrm{g} / \mathrm{mL}$. From this concentration, a series of dilutions down to $0.5 \mu \mathrm{g} / \mathrm{mL}$, was performed.

\subsubsection{Preparation of the Microtiter Plates}

For each test item, $0.1 \mathrm{~mL}$ of previously prepared concentration, were dispensed (two for each concentration) into the wells of a microtiter. Then $0.1 \mathrm{~mL}$ of the adjusted fungal suspensions were added to each well containing the test item solutions. With this operation, a reciprocal dilution of 1:2 either for fungi or for test items, was obtained. The final concentrations were the following: yeast and filamentous fungi: $5 \times 10^{4}$ cells $/ \mathrm{mL}$; dermatophytes: $1 \times 10^{5}$ cells $/ \mathrm{mL}$; test items: from $128 \mu \mathrm{g} / \mathrm{mL}$ to $0.25 \mu \mathrm{g} / \mathrm{mL}$ in a 0.2 $\mathrm{mL}$ of final volume.

The microtiter plates were incubated $48 \mathrm{~h}$ at $35^{\circ} \mathrm{C}$ for yeast and filamentous fungi, or 7 days at $28{ }^{\circ} \mathrm{C}$ for dermatophytes. The minimum inhibitory concentration (MIC) endpoint was defined as the lowest concentration that causes no visible turbidity or, at least, inhibition of growth $\geq 50 \%$ (yeasts) compared with the growth for a drug-free control.

\subsubsection{In Vivo Experiments}

Tolerability studies were performed using female athymic Swiss nude mice. Mice were maintained in laminar flow rooms keeping temperature and humidity constant. Mice had free access to food and water. Experiments were approved by the Ethics Committee for Animal Experimentation of the Istituto Nazionale Tumori of Milan according to institutional guidelines.

Compound 2 was suspended in ethanol-cremophor-water $(10+10+80 \%)$ to a concentration of $10 \mathrm{mg} / \mathrm{mL}$. Mice $(8$ weeks old) were administered orally by a single dose (200 $\mathrm{mg} / \mathrm{kg}$ ). Mice were weighed and monitored daily for 8 days after administration.

The results were as follows: body weight loss: (7\%), lethal toxicity: 0/4. The necropsy of sacrificed animals on day 51 after treatment did not show any signs of disease. 
<smiles>C=CCC(=O)c1cc2c(cc1O)OCO2</smiles>

Scheme 1. Synthesis of compounds 1-4. Reagents and conditions: a) $\mathrm{BF}_{3} \cdot \mathrm{Et}_{2} \mathrm{O}$, propanoic anhydride, $45 \mathrm{~min}, 80{ }^{\circ} \mathrm{C} ; 73 \%$; b) $\mathrm{MeMgBr}$, $\mathrm{Et}_{2} \mathrm{O}, 45 \mathrm{~min}$, r.t.; c) $\mathrm{CH}_{2}=\mathrm{CHCOCl}$, toluene, r.t., 16 h, $66 \%$; d) $\mathrm{CH}_{3} \mathrm{I}$, $\mathrm{K}_{2} \mathrm{CO}_{3}$, acetone, reflux, 10h, quantitative; e) $\mathrm{CH}_{2}=\mathrm{CHCH}_{2} \mathrm{CH}_{2} \mathrm{COCl}$, toluene, r.t., $16 \mathrm{~h}, 19 \%$.

\subsection{8. ${ }^{1}$ H-NMR Study: Thiol-trapping Experiments}

${ }^{1} \mathrm{H}$ NMR spectra were recorded at $25^{\circ} \mathrm{C}$ on a Bruker AV 600 spectrometer operating at a frequency of $600.13 \mathrm{MHz}$ for $1 \mathrm{H}$ nucleus. All chemical shifts were reported in ppm $(\delta)$ and referenced to the chemical shifts of residual solvent resonances.

${ }^{1} \mathrm{H}$ NMR spectroscopy was used to determine the formation of the Michael adduct and allowed us to assess that the reaction was complete. No side products were detected.

The spectrum of compound 2 (25 $\mathrm{mg})$ was acquired in DMSO- $d_{6}$ and all the signals were assigned. Cysteamine (20 $\mathrm{mg}$ ), at molar ratio $\mathrm{R}=[$ cysteamine $] /[2]=2.0$, was directly added into the NMR tube and the spectra were recorded at different times ranging from 5 to 60 minutes. The in situ generated adduct (30 microliters) was then diluted with $\mathrm{CDCl}_{3}(1: 20)$ in order to investigate the reversibility of the Michael reaction.

\section{RESULTS AND DISCUSSION}

\subsection{Synthesis of Compounds 1-4}

Kakuol (1) was obtained in a single step by reaction of sesamol with $\mathrm{BF}_{3} \cdot \mathrm{Et}_{2} \mathrm{O}$ in propanoic anhydride [9]. Compounds 2 and 3 were obtained by reacting the highly coordinating magnesium 3,4-(methylenedioxy)phenolate with the suitable acyl chlorides to introduce the desired acyl moiety directly at the ortho position of phenol group.

Compound $\mathbf{4}$ was prepared by treatment of compound $\mathbf{2}$ with $\mathrm{CH}_{3} \mathrm{I}$ in acetone (Scheme 1).

\subsection{Antifungal Activity of Compounds 1-4}

The antifungal activity of kakuol (1) against dermatophyte fungi and yeasts is presented in Tables 1-3. In

Table 1. Minimum inhibitory concentration of compounds 1-4 and miconazole (MCZ) on dermatophyte fungi.

\begin{tabular}{|c|c|c|c|c|c|}
\hline \multirow[b]{2}{*}{ Dermatophyte Fungi } & \multicolumn{5}{|c|}{$\operatorname{MIC}(\mu \mathrm{g} / \mathrm{mL})$} \\
\hline & 1 & 2 & 3 & 4 & $\mathrm{MCZ}$ \\
\hline Trichophyton rubrum IDI D 1155 & $>32$ & 0.5 & 64.0 & 2.0 & 2.0 \\
\hline Trichophyton mentagrophytes IDI D 1049 & $>32$ & 0.5 & 64.0 & 2.0 & 2.0 \\
\hline Trichophyton quinckeanum NCPF 309 & $>32$ & 0.5 & 64.0 & 2.0 & 2.0 \\
\hline Trichophyton rubrum SG $10 \mathrm{III}$ & & $\leq 0.25$ & & & 1.0 \\
\hline Trichophyton rubrum SG 9 II & & $\leq 0.25$ & & & 0.5 \\
\hline Trichophyton mentagrophytes $S G 1 I$ & & $\leq 0.25$ & & & 0.5 \\
\hline Trichophyton soudanense SG $10 \mathrm{I}$ & & 0.5 & & & 0.5 \\
\hline Trichophyton album SG IDI D 0250 & & 8.0 & & & 8.0 \\
\hline Trichophyton violaceum IDI D $0086 I$ & & $\leq 0.25$ & & & 1.0 \\
\hline Microsporum canis IMM 3864 & $>32$ & 0.5 & $\geq 64.0$ & 64.0 & 2.0 \\
\hline Microsporum canis IDI D 1011 & & $\leq 0.25$ & & & 1.0 \\
\hline Microsporum gipseum $S G 4 I$ & & $\leq 0.25$ & & & 2.0 \\
\hline Epidermophyton floccosum SG 3 III & $>32$ & 0.5 & $\geq 64.0$ & 16.0 & 2.0 \\
\hline Epidermophyton floccosum IDI D 0011 & & $\leq 0.25$ & & & $\leq 0.25$ \\
\hline
\end{tabular}


Table 2. Minimum inhibitory concentration of compounds 1-4 and miconazole (MCZ) on filamentous fungi.

\begin{tabular}{|c|c|c|c|c|c|}
\hline \multirow[b]{2}{*}{ Filamentous Fungi } & \multicolumn{5}{|c|}{$\operatorname{MIC}(\mu \mathrm{g} / \mathrm{mL})$} \\
\hline & 1 & 2 & 3 & 4 & MCZ \\
\hline Fusarium sp. F77 & $>64$ & 2.0 & $\geq 64.0$ & 8.0 & 16.0 \\
\hline Mисот тисеdo АТСС 7941 & $>64$ & 2.0 & $\geq 64.0$ & 8.0 & 16.0 \\
\hline Penicillium sp. 1302 & $>64$ & 8.0 & $\geq 64.0$ & 64.0 & 4.0 \\
\hline Aspergillus niger ATCC 16404 & $>64$ & 8.0 & $\geq 64.0$ & 32.0 & 8.0 \\
\hline Aspergillus fumigatus ATCC 28212 & $>64$ & 8.0 & $\geq 64.0$ & 64.0 & 4.0 \\
\hline Aspergillus fumigatus G.S & & 16.0 & & & 4.0 \\
\hline Scopulariopsis brevicaulis SG 3 II & & 0.5 & & & 8.0 \\
\hline Acremonium sp. SG $11 \mathrm{III}$ & & 4.0 & & & 8.0 \\
\hline
\end{tabular}

Table 3. Minimum inhibitory concentration of compounds 1-4 and miconazole (MCZ) on yeasts.

\begin{tabular}{|c|c|c|c|c|c|}
\hline Yeasts & \multicolumn{5}{|c|}{$\operatorname{MIC}(\mu \mathrm{g} / \mathrm{mL})$} \\
\hline Candida albicans 562 & 128.0 & 8.0 & $\geq 64.0$ & 8.0 & 8.0 \\
\hline Candida tropicalis ISS1 & 128.0 & 4.0 & $\geq 64.0$ & 32.0 & 4.0 \\
\hline Candida albicans IDI D 01011 & & 4.0 & & & 16.0 \\
\hline Candida albicans 3575 & & 4.0 & & & 16.0 \\
\hline Candida albicans SG $2 I I I$ & & 4.0 & & & 4.0 \\
\hline Candida albicans $700-94$ & & 4.0 & & & 16.0 \\
\hline Candida guillermondii ISS 1 & & 8.0 & & & 1.0 \\
\hline Candida krusei IDI D 1046 & & 1.0 & & & 4.0 \\
\hline Candida tropicalis 5705 & & 8.0 & & & 8.0 \\
\hline Saccharomyces cerevisiae ATCC7752 & 128.0 & $<0.25$ & $\geq 64.0$ & 2.0 & $<0.25$ \\
\hline
\end{tabular}

spite of the acceptable results obtained on pathogenic fungi of agricultural interest [8], kakuol showed only weak activity against all tested strains. We thus tested compound $\mathbf{2}$, the most promising analogue from our previous investigation [9].

Interestingly, this molecule showed a broad-spectrum activity against most of the fungal species tested. It resulted particularly effective against dermatophyte strains (Table 1), showing MIC values in the range of $0.25-0.5 \mu \mathrm{g} / \mathrm{mL}$, two/four-fold lower than those of the positive control miconazole (MCZ). The only exception is represented by Trichophyton album.
Compound 2 was generally less effective on filamentous fungi, the MIC values being in the range of $0.5-16 \mu \mathrm{g} / \mathrm{mL}$ (Table 2). Noteworthy, the MIC values of MCZ on these strains ranged between 4 and $16 \mu \mathrm{g} / \mathrm{mL}$.

Moreover, the activity of compound $\mathbf{2}$ on yeasts was in the range of $0.5-8 \mu \mathrm{g} / \mathrm{mL}$, comparable or lower than the activity of MCZ, with the exception of the Candida guillermondii ISS 1 strain (Table 3).

To gain insights into the key features affecting the activity, analogues $\mathbf{3}$ and $\mathbf{4}$ were synthesized. The methoxy derivative 4 was prepared to investigate the role of the 


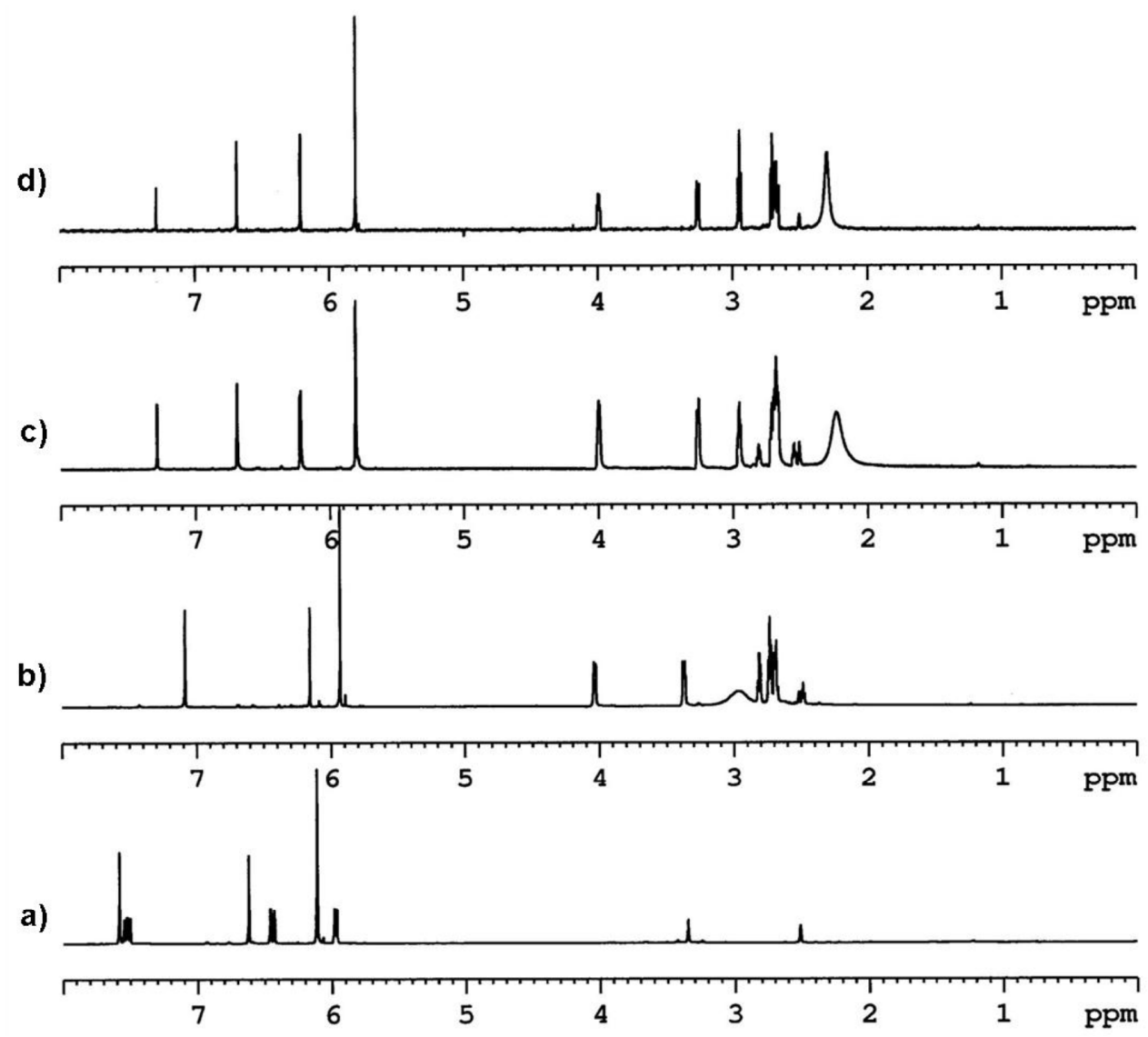

Fig. (2). (a) ${ }^{1} \mathrm{H}$ NMR spectrum of 2 in DMSO- $d_{6}$; (b) spectrum acquired 50 minutes after the addition of cysteamine at R = [cysteamine]/[2] $=2.0$; (c) spectrum of the adduct acquired 5 minutes after the dilution with $\mathrm{CDCl}_{3}(1: 20)$; (d) spectrum of the adduct acquired $48 \mathrm{~h}$ after the dilution.

phenol group. MIC values of compound 4 against all the tested strains were generally higher than MICs of compound 2, however lower than those of the natural compound kakuol (Tables 1-3).

The role of the $\alpha, \beta$-unsaturated carbonyl group was confirmed by examining compound $\mathbf{3}$ bearing a double bond two carbon atoms away from the carbonyl group. The compound resulted less effective than compound 2 against all the tested strains (Tables 1-3). Overall, these results indicate that the conjugation between the double bond and the carbonyl group is a stringent structural requirement for the activity.

The $\alpha, \beta$-unsaturated ketone functionality is well established as a Michael acceptor for trapping thiols [12]. Covalent binding of thiols represents an important mechanism of bioactivity and many biologically relevant pathways are targeted by thiol-reactive compounds [12]. Research on Michael acceptors has been recently rekindled by the FDA approval of the covalent kinase inhibitors afatinib and ibrutinib, containing acrylic acid amide groups [13].

To highlight the affinity of compound $\mathbf{2}$ towards thiols, we applied a simple NMR method recently developed by Avonto and coworker [14]. The ${ }^{1} \mathrm{H}$ NMR spectrum of compound 2 was acquired in DMSO- $d_{6}$ (Fig. 2, see experiment for details) in the presence of cysteamine. After 50 minutes the total disappearance of signals attributed to the double bond and the appearance of the $\mathrm{CH}_{2}$ signals proved that the addition of cysteamine to the double bond was quantitative. The solution of the in situ generated adduct was then diluted with $\mathrm{CDCl}_{3}$ : 48 hours after the dilution no signals belonging to the double bond reappeared (Fig. 2), indicating that the addition of cysteamine to compound $\mathbf{2}$ did not show any solvent-induced reversibility.

The above observations suggest that, as expected, the reactive acrylic group of compound $\mathbf{2}$ is prone to a fast covalent binding mode to thiols. This can obviously cause concern with respect to its chemoselectivity [15].

However, it is noteworthy that in biological systems the reactivity of individual fragments strongly depends on the structure of the reacting proteins [16]. New approaches to identify preferred binding sites of covalently binding fragments have recently been developed [17]. Interestingly, reactive groups like acrylates in proteins have been found to give remarkable and rather unexpected chemoselectivity [18, 19]. Numerous research groups are currently involved in developing specific covalently binding inhibitors [16] and many approaches based on the use of covalent fragments as a starting point for lead-generation campaigns have been published to date $[20,21]$. 
Preliminary in vivo studies, performed to shed light on the tolerability of compound $\mathbf{2}$, showed that this molecule was not toxic when orally administered to mice in a single dose of $200 \mathrm{mg} / \mathrm{kg}$ (see experimental for details).

\section{CONCLUSION}

The present paper describes the evaluation of novel derivatives of the natural compound kakuol as potential antifungals for human treatment. In particular compound $\mathbf{2}$, due to its remarkable in vitro activity, can be considered an interesting scaffold for the design of new chemotherapeutic agents. The results call for follow-up studies to further investigate the compound metabolism and its behaviour in biological systems.

\section{CONSENT FOR PUBLICATION}

Not applicable.

\section{CONFLICT OF INTEREST}

The authors declare no conflict of interest, financial or otherwise.

\section{ACKNOWLEDGEMENTS}

The Authors thank Dr. M. R. Lucreziotti and G. Gramiccioli for helpful cooperation.

\section{REFERENCES}

[1] Campoy, S.J.; Adrio, J.L. Antifungals. Biochem. Pharmacol. 2016, 86-96.

[2] Brown, G.D.; Denning, D.W.; Neil, A.R.; Gow. N.A.R.; Levitz, S.M.; Netea, M.G.; White, T.C. Hidden Killers: Human Fungal Infections. Sci. Transl. Med. 2012, 4, 165rv13.

[3] Zahur, M.; Afroz, A.; Rashid, U.; Khaliq, S. Dermatomycoses: Challenges and Human Immune Responses. Curr. Protein Peptide Sci. 2014, 15, 437-444.

[4] Pfaller, M.A.; Rhomberg, P.R.; Messer, S.A.; Jones, R.N.; Castanheira, M. Isavuconazole, micafungin, and 8 comparator antifungal agents' susceptibility profiles for common and uncommon opportunistic fungi collected in 2013: temporal analysis of antifungal drug resistance using CLSI species-specific clinical breakpoints and proposed epidemiological cutoff values. Diagn Microbiol Infect Dis 2015, 82, 303-313.
[5] Pianalto, K.M.; Alspaugh, J.A. New horizons in antifungal therapy J. Fungi 2016, 2, 1-24.

[6] Perfect, J.R. Is there an emerging need for new antifungals? Expert Opin. Emerg. Drugs 2016, 21, 129-131.

[7] Newman, D.J.; Cragg, G.M. Natural Products as Sources of New Drugs from 1981 to 2014. J. Nat. Prod. 2016, 79, 629-661.

[8] Lee, J.Y.; Moon, S.S.; Hwang, B.K. Isolation and antifungal activity of kakuol, a propiophenone derivative from Asarum sieboldii rhizome. Pest. Manag. Sci. 2005, 61, 821-825.

[9] Musso, L.; Dallavalle, S.; Merlini, L.; Farina, G. Synthesis and Antifungal Activity of 2-Hydroxy-4,5-methylenedioxyaryl Ketones as Analogues of Kakuol. Chem. Biodiv. 2007, 7, 887-897.

[10] Rodriguez-Tudela, J.L.; Barchiesi, F.; Bille, J.; Chryssanthou, E.; Cuenca-Estrella, M.; Denning, D.; Donnelly, J.P.; Dupont, B.; Fegeler, W.; Moore, C.; Richardson, M.; Verweij, P.E. Method for the determination of minimum inhibitory concentration (MIC) by broth dilution of fermentative yeasts European Committee for Antimicrobial Susceptibility Testing (EUCAST). Clin. Microbiol. Infect. 2003, 9, 1-8.

[11] da Silva Barros, M. E.; de Assis Santos, D.; Hamdan, J. S. In vitro methods for antifungal susceptibility testing of Trichophyton spp. Mycol. Res. 2006, 110, 1355-1360.

[12] Amslinger, S. The Tunable Functionality of $\alpha, \beta$-Unsaturated Carbonyl Compounds Enables Their Differential Application in Biological Systems. Chem. Med. Chem. 2010, 5, 351-356.

[13] Singh, J.; Petter, R.C.; Baillie, T.A.; Whitty, A. The resurgence of covalent drugs. Nat. Rev. Drug Discovery 2011, 10, 307-317.

[14] Avonto, C.; Taglialatela-Scafati, O.; Pollastro, F.; Minassi, A.; Di Marzo, V.; De Petrocelli, L.; Appendino, G. An NMR Spectroscopic Method to Identify and Classify Thiol-Trapping Agents: Revival of Michael Acceptors for Drug Discovery? Angew. Chem. Int. Ed. 2011, 50, 467-471.

[15] Pouliot, M.; Jeanmart, S. Pan Assay Interference Compounds (PAINS) and Other Promiscuous Compounds in Antifungal Research. J. Med. Chem. 2016, 59, 497-503.

[16] Backus, K.M.; Correia, B.E.; Lum, K.M.; Forli, S.; Horning, B.D.; Gonzalez-Paez, G.E.; Chatterjee, S.; Lanning, B.R.; Teijaro, J.R.; Olson, A.J.; Wolan, D.W.; Cravatt, B.F. Proteome-wide covalent ligand discovery in native biological systems. Nature 2016, 534, 570-574

[17] Plettenburg, O. What Do Reactive Fragments Actually Do in Cells? Angew. Chem. Int. Ed. 2017, 56, 446-448.

[18] Kathman, S.G.; Xu, Z.; Statsyuk, A.V. A Fragment-Based Method to Discover Irreversible Covalent Inhibitors of Cysteine Proteases. J. Med. Chem. 2014, 57, 4969-4974.

[19] Jöst, C.; Nitsche, C.; Scholz, T.; Roux, L.; Klein, C.D. Promiscuity and Selectivity in Covalent Enzyme Inhibition: A Systematic Study of Electrophilic Fragments. J. Med. Chem. 2014, 57, 7590-7599.

[20] Kathman, S.G.; Statsyuk, A.V. Covalent tethering of fragments for covalent probe discovery. MedChemComm 2016, 7, 576-585.

[21] Miller, R.M.; Paavilainen, V.O.; Krishnan, S.; Serafimova, I.M.; Taunton, J. Electrophilic Fragment-Based Design of Reversible Covalent Kinase Inhibitors. J. Am. Chem. Soc. 2013, 135, 52985301. 